\title{
The utility of endoscopic ultrasonography and endoscopy in the endoscopic mucosal resection of early gastric cancer
}

S Ohashi, K Segawa, S Okamura, M Mitake, H Urano, M Shimodaira, T Takeda, S Kanamori, T Naito, K Takeda, B Itoh, H Goto, Y Niwa, T Hayakawa

\begin{abstract}
Objective-To clarify the usefulness of endoscopic ultrasonography (EUS) and endoscopy in the endoscopic mucosal resection (EMR) of early gastric cancer. Patients/Methods-EMR was performed in 61 patients with early gastric cancer over the past five years. The accuracy of the assessment of the depth of cancerous invasion was studied in 49 patients who had EUS before EMR. Forty eight patients were treated with endoscopy alone; in these patients, EUS and endoscopic findings correlated with the clinical course.

Results-Forty six patients showed no changes in the submucosal layer or deeper structures on EUS. Pathologically these included 37 patients with mucosal cancer and nine with submucosal cancer showing very slight submucosal infiltration. Three patients showed diffuse low echo changes in the submucosal layer on EUS; pathologically, these included two with submucosal cancer and one with mucosal cancer with a peptic ulcer scar within the tumour focus. Of 48 patients receiving endoscopic treatment alone, 45 showed no tumour recurrence or evidence of metastases on EUS and endoscopy. Three cases of recurrence were observed. Two of these patients had a surgical gastrectomy, and one was re-treated endoscopically. In the former cases, the surgical results correlated well with assessment by EUS and endoscopy. In addition, the latter patient who was re-treated endoscopically after evaluation with EUS and endoscopy has so far had no recurrence.

Conclusion-The combined use of EUS and endoscopy is effective in diagnosing the depth of cancerous invasion in patients undergoing EMR as well as in clarifying changes both within and between anatomic levels during follow up. (Gut 1999;45:599-604)
\end{abstract}

Keywords: endoscopic ultrasonography; endoscopy; mucosal resection; gastric cancer

The incidence of early gastric cancer is high in Japan. Radiological and endoscopic examination are extremely useful in the non-invasive diagnosis of gastric carcinoma. Endoscopic ultrasonography (EUS) allows a more detailed study of the structures of the gastrointestinal wall and of abnormalities of the lymph nodes by directly imaging target lesions with a high frequency ultrasonic beam directed from within the intestinal lumen. ${ }^{12}$ These modalities have made it possible to detect gastric cancer earlier, thereby improving prognosis. In addition, with the advent of new endoscopic techniques such as strip biopsy, therapeutic endoscopy is now playing a more important role in the management of early gastric cancer. $^{3-5}$ This study was carried out to clarify the usefulness of EUS and endoscopy in endoscopic mucosal resection (EMR) of early gastric cancer.

\section{Materials and methods}

EMR was performed in 61 patients with early gastric cancer seen at our institution over the past five years. The median age of the patients (47 men and 14 women) was 69.6 years.

HISTOLOGICAL AND EUS ASSESSMENT OF THE DEPTH OF TUMOUR INFILTRATION AT EMR

The accuracy of the assessment of the depth of cancerous invasion was studied in 49 patients (40 men and nine women) who had EUS before EMR. The results of these investigations were correlated with detailed histological examination of the resected specimens. In the other 12 patients only endoscopy was performed before EMR.

\section{AFTER EMR}

In all, 48 of the 61 patients (35 men and 13 women) were treated with endoscopy alone; in these patients, EUS and endoscopic findings correlated with the clinical course. All patients were followed up after treatment at three month intervals for the first year and annually thereafter. At follow up examinations, endoscopy was performed and multiple biopsy specimens taken. EUS was performed annually if possible or when tumour recurrence was suspected. In the other 13 patients, EMR disclosed submucosal cancer or a resection margin positive for tumour; these patients were treated by radical gastrectomy with lymph node dissection a few days after EMR.

EMR was performed using the strip biopsy technique. $^{3-5}$ The use of a double channel fibreoptic scope allowed mucosal manipulation. The snare was introduced through one channel, and the area to be resected was grasped and lifted out through the other

Abbreviations used in this paper: EUS, endoscopic ultrasonography; EMR, endoscopic mucosal resection. 
Table 1 Histological and endoscopic ultrasonography (EUS) assessment of the depth of tumour infiltration

\begin{tabular}{llll}
\hline & \multicolumn{2}{c}{ EUS findings } & \\
\cline { 2 - 3 } Histology & $m$ cancer & sm cancer & Total \\
\hline m cancer & 37 & $1^{\star \star}$ & 38 \\
sm cancer & $9^{\star}$ & 2 & 11 \\
Total & 46 & 3 & 49 \\
\hline
\end{tabular}

$\mathrm{m}$ cancer, tumour limited to the mucosa; sm cancer, tumour extending into the submucosa.

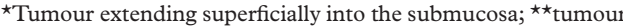
limited to the mucosa, with peptic ulcer scarring in the tumour focus.

Table 2 Cumulative follow up years after endoscopic mucosal resection (EMR) and numbers in each group

\begin{tabular}{lllll}
\hline Years & $A$ & $B$ & $C$ & Total \\
\hline 0 & 21 & 10 & 17 & 48 \\
$\leqslant 1$ & $16(12)$ & $6(5)$ & $13(6)$ & 35 \\
$\leqslant 2$ & $13(5)$ & $3(1)$ & $7(4)$ & 23 \\
$\leqslant 3$ & $10(4)$ & $3(0)$ & $1(0)$ & 14 \\
\hline
\end{tabular}

Numbers in parentheses are numbers of patients undergoing endoscopic ultrasonography one, two, or three years after EMR as applicable.

Group A, 21 patients with mucosal cancer, a negative stump, and no peptic ulcer in the tumour focus at endoscopic one step resection; group B, 10 patients with mucosal cancer, no peptic ulcer in the tumour focus, and a negative stump probably at endoscopic piecemeal resection; group C, 10 patients with mucosal cancer at EMR who were re-treated by laser or coagulation therapy because of incomplete resection, two patients with mucosal cancer, a negative stump, and peptic ulcer scar in the tumour focus at EMR, and five patients with submucosal cancer at EMR.

channel. It was also possible to facilitate mucosal manipulation by inducing mucosal swelling by submucosal injection of hypertonic saline/adrenaline (epinephrine). Procedures such as electrocoagulation, ethanol injection, and Nd-YAG laser endoscopic treatment were occasionally used.

An Olympus Aloka Radial Sector EUS apparatus (GF-UM2 or GF-UM3) with a wave frequency of either 7.5 or $12 \mathrm{MHZ}$ was used. The echo probe was routinely covered with a water filled balloon so as to obtain accurate real time sonographic imaging. The normal gastric wall is usually visualised on EUS as a five layered structure, ${ }^{6}$ each layer corresponding to an anatomic level. Using this system, we determined the depth of tumour infiltration and the presence of peptic ulceration within the tumour. The EUS criterion for lymph node metastasis was a node with a round, well defined, non-homogeneous, hypoechoic pattern which was more than $5 \mathrm{~mm}$ at its smallest diameter. The depth of tumour invasion was determined after histological examination in patients treated by endoscopic resection.

Early gastric cancer was defined according to the 1962 criteria of the Japanese Society of Gastroenterological Endoscopy, as gastric adenocarcinoma confined to the mucosa or submucosa.

\section{Results}

HISTOLOGICAL AND EUS ASSESSMENT OF THE DEPTH OF TUMOUR INFILTRATION AT EMR

Forty six patients showed no changes in the submucosal layer or deeper structures on EUS. Histologically these included 37 patients with mucosal cancer and nine with submucosal cancer showing very slight submucosal infiltration. Three patients showed diffuse low echo changes in the submucosal layer on EUS; these included two with submucosal cancer and one with mucosal cancer with a peptic ulcer scar within the tumour detected histologically (table 1).

FOLLOW UP AFTER EMR

The 48 patients treated by EMR were divided into three groups as follows: A, 21 patients treated by endoscopic one step resection; B, 10 patients treated by endoscopic piecemeal resection; C, 17 patients who were treated endoscopically because of surgical risk factors, advanced age, or refusal to have surgical treatment (table 2).

EUS FOLLOW UP

One year after EMR, nine out of 12 patients in group A showed Ul-IIs changes resembling benign ulcers on EUS, one showed Ul-IIs IIIs changes in the submucosal layer or deeper, and two showed no change (see table 3 for definition of Ul-IIs and Ul-IIs IIIs). Four out of five patients in group B showed Ul-IIs changes and one showed Ul-IIs IIIs changes. Four out of six patients in group $\mathrm{C}$ showed Ul-IIs changes and two showed Ul-IIs IIIs changes. No abdominal lymphadenopathy was observed in any of the patients (table 3 ).

Two years after EMR, all five group A, one group $\mathrm{B}$, and two group $\mathrm{C}$ patients showed Ul-IIs changes on EUS. One group C patient showed no changes. Another group C patient showed Ul-IIs IIIs changes. No abdominal lymphadenopathy was observed in any of the patients (table 3 ).

Three years after EMR, two group A patients showed Ul-IIs changes and two further group A patients showed no changes on EUS (table 3).

ENDOSCOPIC FOLLOW UP

One year after EMR, 14 out of 16 patients in group A showed s1 s2 ulcer scars, while two showed Yamada type II protrusions (Y II). Five out of six patients in group B showed s1 s2

Table 3 Endoscopic ultrasonography (EUS) findings one, two, and three years after endoscopic mucosal resection (EMR)

\begin{tabular}{llll}
\hline Group & & \\
\cline { 2 - 4 } & Total
\end{tabular}

1 year after EMR

$\begin{array}{llr}1 \text { year after EMR } & & \\ \text { No change } & 2 & 2\end{array}$

$\begin{array}{lllll}\text { Ul-IIs } & 9 & 4 & 4 & 17 \\ \text { Ul-IIs IIIs } & 1 & 1 & 2\end{array}$

$\begin{array}{lrrrr}\text { Ul-IIs } \sim \text { IIIs } & 1 & 1 & 2 & 4 \\ \text { Total } & 12 & 5 & 6 & 23\end{array}$

2 years after EMR

No change

$\begin{array}{lllll}\text { Ul-IIs } & 5 & 1 & 1 & 1\end{array}$

$\begin{array}{lllll}\text { Ul-IIs } & 5 & 1 & 2 & 8 \\ \text { Ul-IIs IIIs } & & & 1 & 1\end{array}$

Ul-IIs IIIs $\quad 5 \quad 1101$

3 years after EMR

No change

Ul-IIs 2

Ul-IIs IIIs

Total 4

Ul-IIs; peptic ulcer scar with fibrosis extending into the submucosa,

Ul-IIs or IIIs; peptic ulcer scar with fibrosis extending into the submucosa or the muscularis propria.

No lymphadenopathy was detected by EUS in any cases. 
Table 4 Endoscopic findings one, two, and three years after endoscopic mucosal resection (EMR)

\begin{tabular}{|c|c|c|c|c|}
\hline & \multicolumn{3}{|c|}{ Group } & \multirow[b]{2}{*}{ Total } \\
\hline & $A$ & $B$ & $C$ & \\
\hline \multicolumn{5}{|c|}{1 year after $E M R$} \\
\hline s1 s2 & 14 & 5 & 11 & 30 \\
\hline Y II & 2 & 1 & 2 & 5 \\
\hline Total & 16 & 6 & 13 & 35 \\
\hline \multicolumn{5}{|c|}{2 years after $E M R$} \\
\hline $\mathrm{s} 1 \sim \mathrm{s} 2$ & 11 & 3 & 5 & 19 \\
\hline Y II & 2 & & 2 & 4 \\
\hline Total & 13 & 3 & 7 & 23 \\
\hline \multicolumn{5}{|c|}{3 years after EMR } \\
\hline $\mathrm{s} 1 \sim \mathrm{s} 2$ & 10 & 3 & 1 & 14 \\
\hline \multicolumn{5}{|l|}{ Y II } \\
\hline Total & 10 & 3 & 1 & 14 \\
\hline
\end{tabular}

s1 s2, ulcer scar; Y II, Yamada type II protrusion.
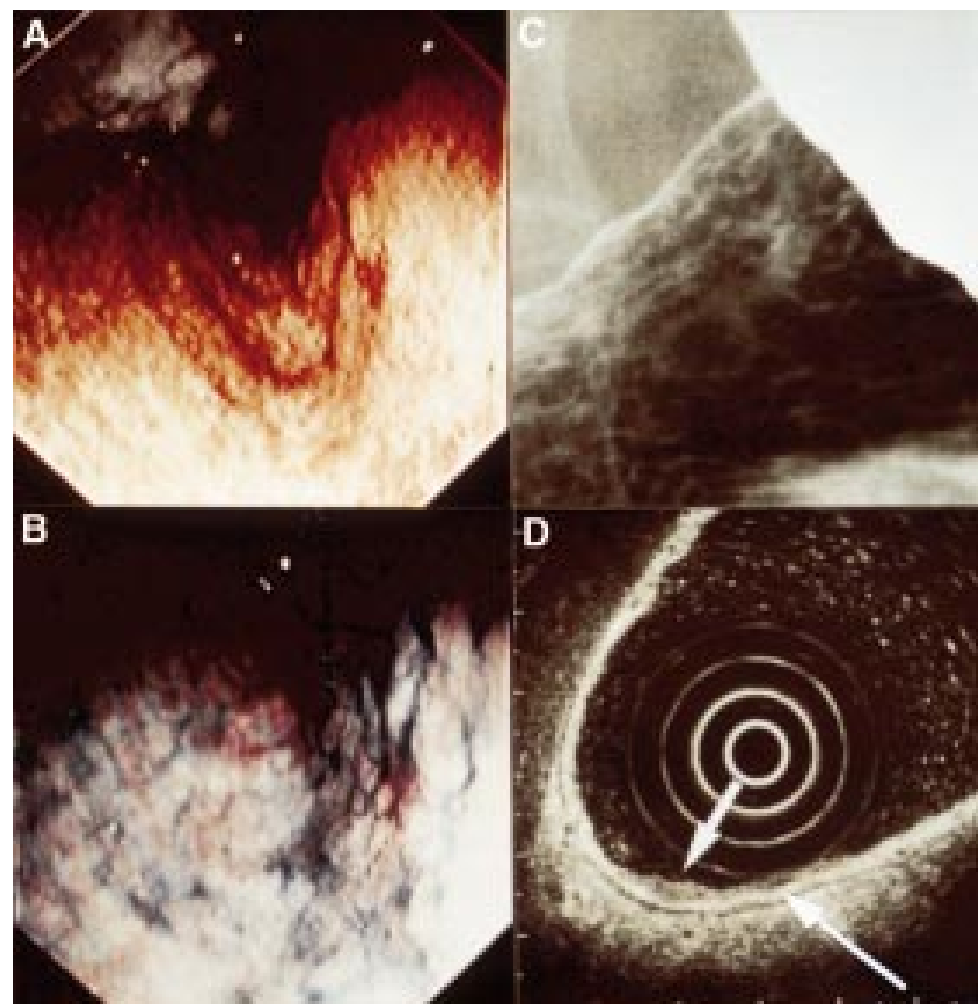

Figure 1 A group A patient with mucosal cancer, a negative stump, and no ulcer in the tumour focus at endoscopic one step resection. Type IIc early cancer before endoscopic resection. (A) Normal endoscopic picture; (B) indigo carmine spray endoscopic picture; (C) double contrast radiograph; (D) endoscopic ultrasonography showing no change in the submucosal layer or deeper.

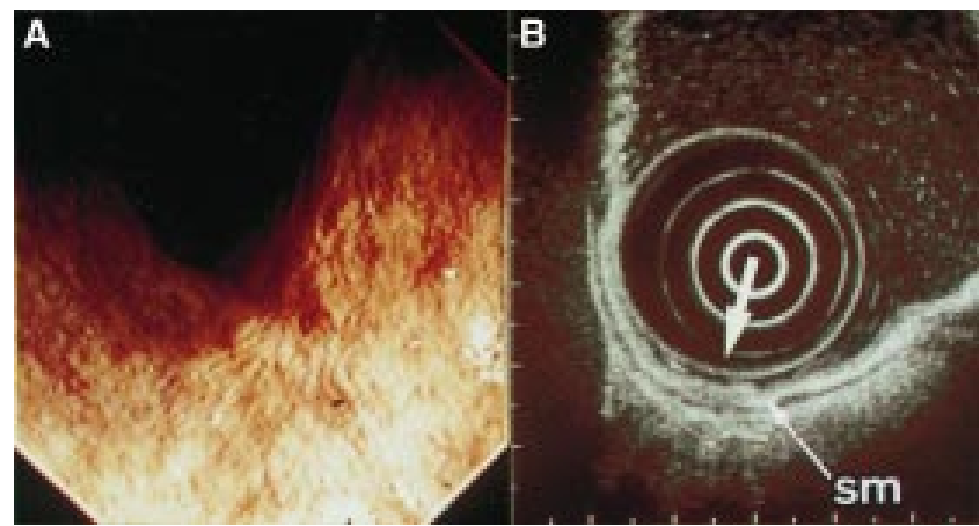

Figure 2 One year after endoscopic mucosal resection. (A) Endoscopic picture showing s1 scar; (B) endoscopic ultrasonography shows Ul-IIs changes resembling benign ulcer. No lymphadenopathy is observed.

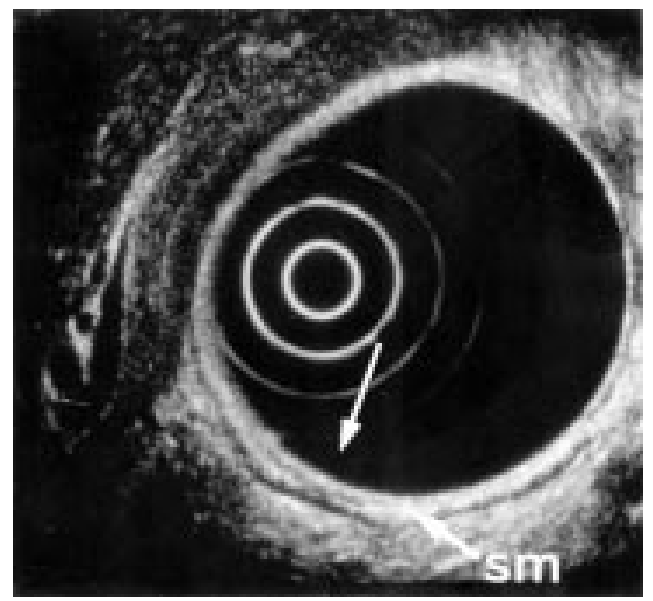

Figure 3 Three years and one month after endoscopic mucosal resection. Endoscopic ultrasonography shows Ul-IIs changes resembling benign ulcer. No lymphadenopathy is observed. sm, submucosal.

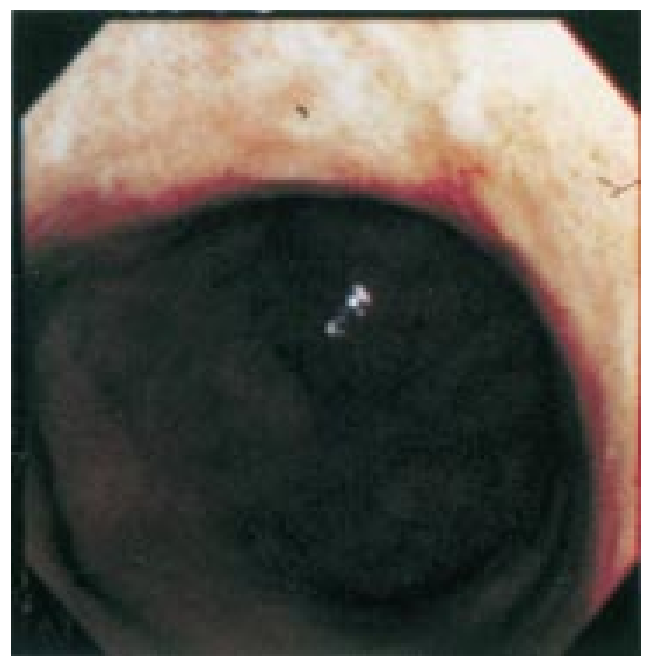

Figure 4 Three years and nine months after endoscopic mucosal resection. Endoscopic picture showing s2 scar.

ulcer scars and one showed Y II. Eleven out of 13 patients in group C showed s1 s2 ulcer scars and two showed Y II (table 4).

Two years after EMR, 11 out of 13 group A patients showed s1 s2 ulcer scars on endoscopy and two showed Y II. All three group B patients showed s1 s2 ulcer scars. Five group C patients showed s1 s2 ulcer scars and two showed Y II (table 4).

Three years after EMR, 10 group A patients, three group B patients, and one group C patient showed s1 s2 ulcer scars (table 4).

CLINICAL COURSES OF PATIENTS UNDERGOING EMR Of the 48 patients who had endoscopic resection, 45 showed a complete response (all 21 group A patients, eight of 10 group B patients, and 16 of 17 group $\mathrm{C}$ patients) (figs 1-4) and three suffered a recurrence (two in group B, one in group C). Of the latter, two had surgical gastrectomy, and one was re-treated endoscopically (figs 5-8).

CLINICAL COURSES OF PATIENTS RECOGNISED AS HAVING A RECURRENCE AFTER EMR

Figure 9 gives the results for EUS and endoscopic appearance and histology of the 

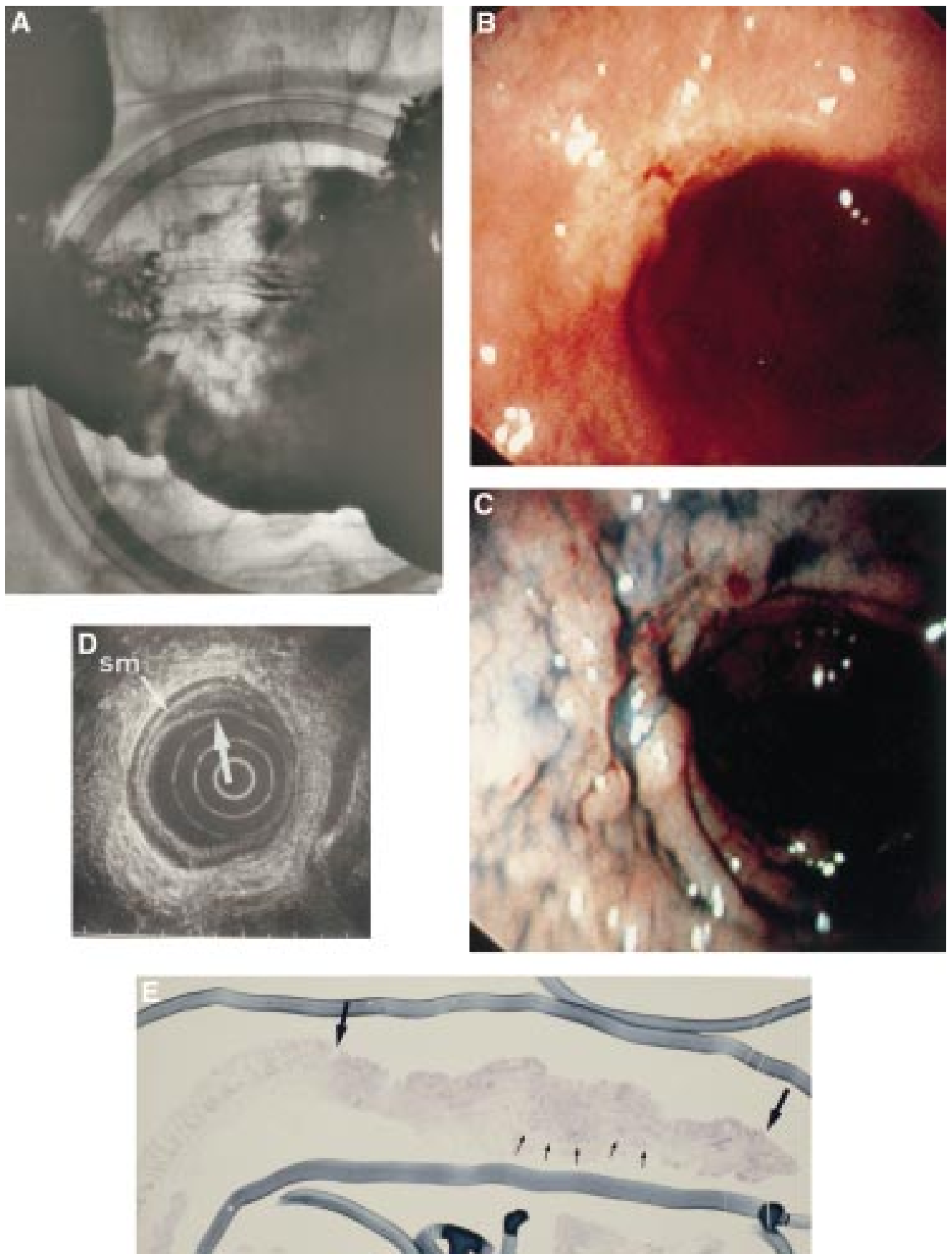

Figure 5. A group C patient with submucosal cancer (slight invasion of submucosa) showing a negative stump at endoscopic piecemeal resection. He refused surgery (recurrent; fig 9C). (A) Double contrast radiograph; (B) normal endoscopic picture; $(C)$ indigo carmine spray endoscopic picture; (D) endoscopic ultrasonography shows no change in the submucosal (sm) layer or deeper; (E) a cross section.

resected specimens from the three patients with a recurrence. The time to clinical recurrence in these three patients was four months, one year, and two years after EMR respectively. These recurrences were assessed as mucosal cancers by EUS and endoscopy. Two patients had surgery. The depth of tumour infiltration was mucosal. Neither had lymph node metastasis.

\section{Discussion}

Progress in endoscopy is the key to improved earlier detection of malignant lesions. The endoscopic patterns of early gastric cancers were accurately described in Japan more than
30 years ago. Whereas endoscopy is of value in staging gastric tumours, EUS is currently the best pretreatment staging procedure, with an accuracy of assessing the depth of invasion of over $90 \% .{ }^{78}$ With EUS, the depth of tumour infiltration is determined by detecting the extent of the ultrasonographic changes produced by the tumour. Patient selection for curative endoscopic treatment depends on the classification of tumours as superficial or nonsuperficial, based on identification of the median hyperechoic layer relative to the submucosa on EUS. In this study, patients showing no changes in the submucosal layer or deeper on EUS included patients with mucosal 


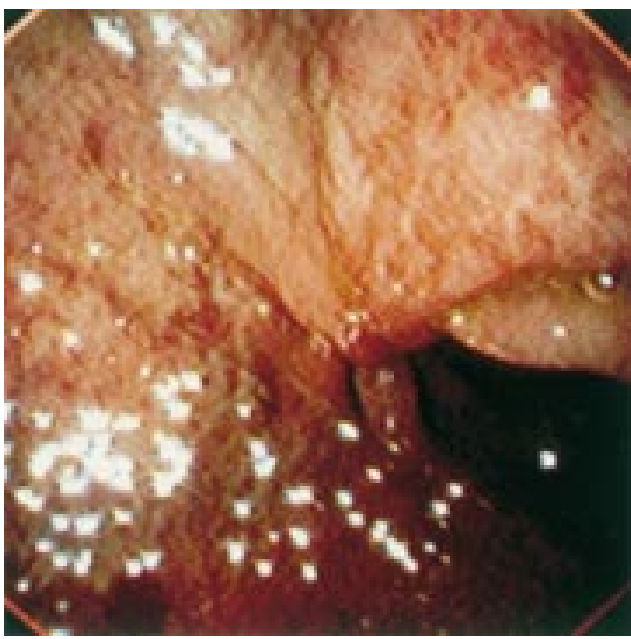

Figure 6 One year after endoscopic mucosal resection. Endoscopic picture showing s2 scar. Biopsy specimen gave negative results for cancer.
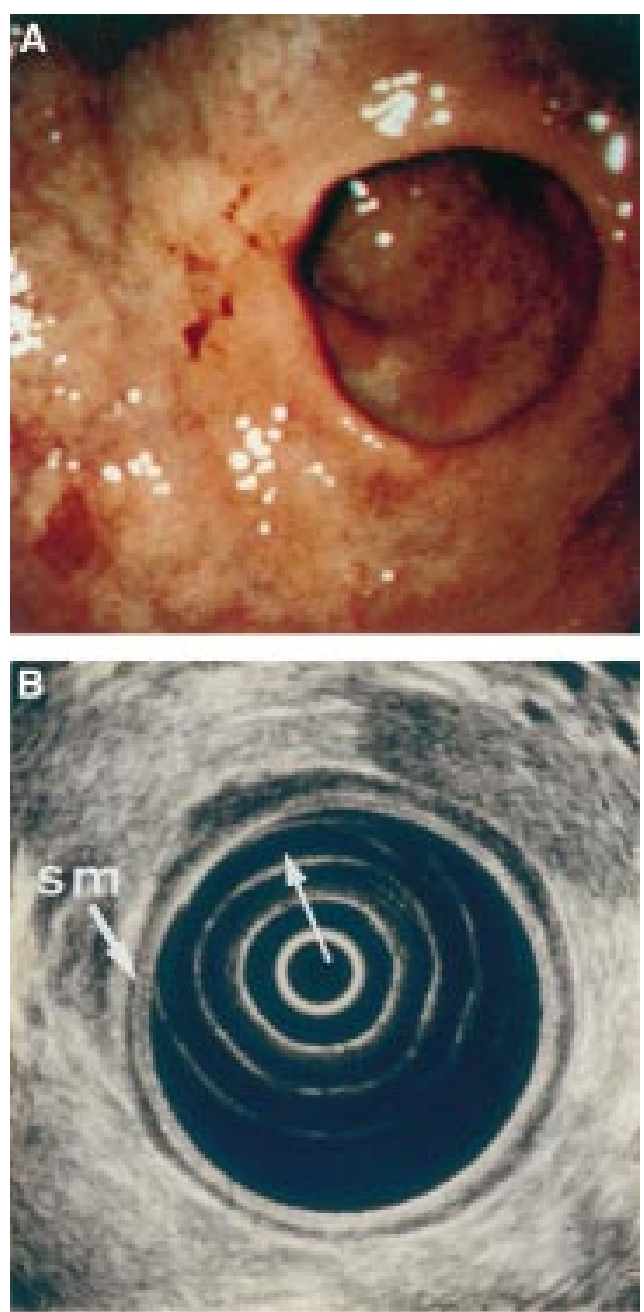

Figure 7 Two years after endoscopic mucosal resection. (A) Endoscopic picture showing s2 scar-like appearance. Biopsy specimen gave positive results for cancer.

(B) Endoscopic ultrasonography shows Ul-IIs changes resembling benign ulcer. No lymphadenopathy is observed. sm, submucosal.

cancer $(80 \%)$ and those with submucosal cancer showing very slight infiltration into the submucosa $(20 \%)$ pathologically. EUS also allowed detection of the existence and assess-

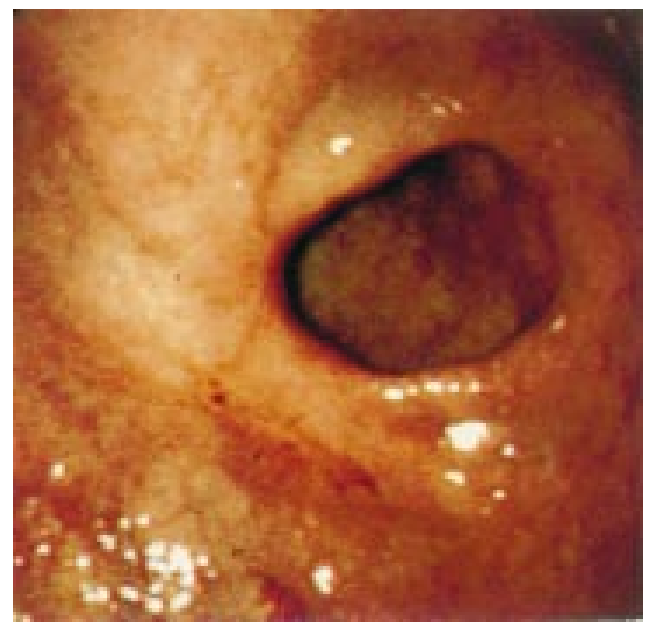

Figure 8 Two years and nine months after endoscopic mucosal resection and seven months after endoscopic combined treatment (laser and pure ethanol injection). Endoscopic picture showing s2 scar. A biopsy specimen gave negative results for cancer.

ment of the depth of peptic ulceration in tumours before EMR. Furthermore, the specificity of identification of the lymph nodes involved was greater than $80 \%$. Therefore EUS assessment is required before deciding on the use of endoscopy for initial treatment.

The adequacy of tumour resection is assessed by examination of the specimen: staging of the depth of tumour invasion, control of the margin of excision, and grading of malignancy. ${ }^{910}$ After endoscopic resection has been performed, the lesion may be classified as intramucosal or submucosal. In the latter, surgical resection is required. It is necessary for patients selected for curative endoscopic treatment to have mucosal carcinoma, to not have peptic ulceration within the tumour focus, and to have more than $2 \mathrm{~mm}$ between the tumour margin and the specimen edge. In this study, patients in whom curative endoscopic treatment could be performed were followed up for more than one year after EMR. They showed Ul-IIs IIIs changes resembling benign ulcer scarring on EUS ${ }^{11}$ and benign ulcer scars or Yamada type II protrusions endoscopically. These patients were negative for cancer on follow up biopsies. No lymphadenopathy was observed.

In patients who cannot be cured by EMR alone, combined endoscopic treatment modalities such as additional endoscopic resection, laser therapy, coagulation therapy, and pure ethanol injection are used widely for those at high risk for surgery, those of advanced age, and those who reject surgery. In this study, after endoscopic combined therapy, 17 patients were followed up endoscopically because of surgical risk factors, age, or refusal to have surgical treatment. On follow up examination, only one patient in this group had cancer on follow up biopsies. Combined assessment by EUS, endoscopy, and EMR specimen histology was very effective in planning the treatment of patients who could not be cured by EMR alone.

When residual or recurrent lesions are detected on follow up examination, treatment 
(A) 67 year old man (group B)

EUS diagnosis before EMR: mucosal cancer, $\mathrm{n}(-)$.

Pathological diagnosis: Ila, mucosal cancer, probably a negative stump at endoscopic piecemeal resection.

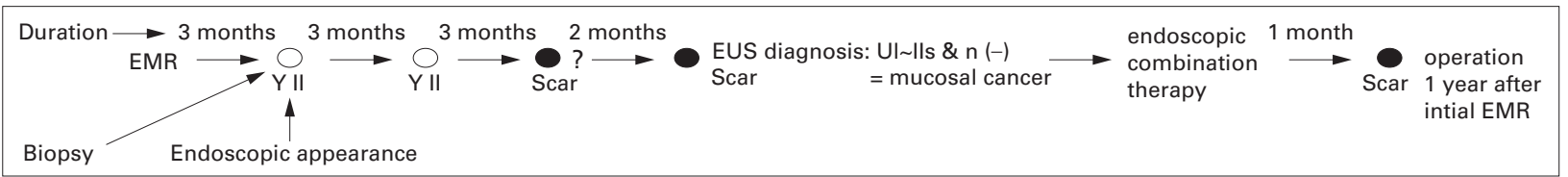

Final diagnosis for surgical specimen: mucosal cancer, ly0, v0, n (-)

(B) 80 year old man (group C)

EUS diagnosis before EMR: mucosal cancer, $\mathrm{n}(-)$.

Pathological diagnosis: Ilc, submucosal cancer, (submucosal slight invasion), a negative stump at endoscopic piecemeal resection.

The patient refused surgery.

Endoscopic
combination therapy

(C) 65 year old woman (group B)

EUS diagnosis before EMR: mucosal cancer, $\mathrm{n}(-)$.

Pathological diagnosis: Ila, mucosal cancer, probably a negative stump at endoscopic piecemeal resection.

$\mathrm{EMR} \stackrel{1 \text { month }}{\longrightarrow} \bigcirc_{\text {Small ulcer }} \stackrel{1 \text { month }}{\longrightarrow} \underset{\mathrm{Ila}}{\stackrel{2}{2} \stackrel{\text { months }}{\longrightarrow} \rightarrow \mathrm{Ila}} \longrightarrow \begin{aligned} & 4 \text { months after initial EMR } \\ & \text { operation }\end{aligned}$

Final diagnosis for surgical specimen: mucosal cancer, ly0, v0, n (-)

Cancer negative on follow up biopsy Cancer positive on follow up biopsy

Figure 9 Endoscopic ultrasonography (EUS), endoscopic, and histological findings for three patients with recurrence of gastric cancer after endoscopic mucosal resection (EMR). Ul-IIs on EUS, ulcer scar image resembling benign ulcer and no tumour invasion or ultrasonographic changes.

of these lesions should be based on evaluation of the patient's clinical status and the degree of histological atypia as determined by identifying changes both within and between anatomic levels. For decision analysis, the endoscopic options such as endoscopic resection and laser and coagulation therapy compete with surgical resection and non-surgical alternatives such as chemotherapy. In this study, two patients had surgical gastrectomy, and one was re-treated by endoscopic procedures. The surgical results correlated well with assessment by EUS and endoscopy. In addition, one patient who was re-treated endoscopically after evaluation using EUS and endoscopy has not so far had any recurrence and has a good quality of life. Thus a combination of EUS and endoscopy is a very reliable diagnostic method.

CONCLUSION

The combined use of EUS and endoscopy is effective in diagnosing the depth of cancerous invasion in patients undergoing EMR as well as in clarifying changes both within and between anatomic levels during follow up.
1 Tio TL, Tytgat GN. Endoscopic ultrasonography in the assessment of intra and transmural infiltration of tumours in the oesophagus, stomach and papilla of Vater and in the detection of extraoesophageal lesions. Endoscopy 1984;16:203-10.

2 Strohm WD, Classen M. Staging of gastric and esophageal carcinoma by means of endoscopic ultrasonography. Scand Gastroenterol 1987;22:17-21.

3 Hirao M, Masuda K, Asanuma T. Endoscopic resection of early gastric cancer and other tumours with local injection of hypertonic saline-epinephrine. Gastrointest Endosc 1988; 34:264-9.

4 Karita $M$, Tada $M$, Okita $K$. The successive strip biopsy partial resection technique for large early gastric and colon cancers. Gastrointest Endosc 1992;38:174-8.

5 Takekoshi T, Baba Y, Ota H. Endoscopic resection of early gastric carcinoma: results of a retrospective analysis of 308 cases. Endoscopy 1994;26:352-8.

6 Aibe T, Fuji T, Okita K, et al. A fundamental study of normal layer structure of the gastrointestinal wall visualized by endoscopic ultrasonography. Scand f Gatroenterol 1986;21: 6-15

7 Ohashi S, Nakazawa S, Yoshino J. Endoscopic ultrasonography in the assessment of invasive gastric cancer. Scand $\mathcal{F}$ Gatroenterol 1989;24:1039-48.

8 Lambert R. Curative endoscopic treatment of early esophageal and gastric cancer. Bildgebung 1993;60(suppl 1):8-12.

9 Tada M, Karita M, Yanai H, et al. Evaluation of endoscopic strip biopsy therapeutically used for early gastric cancer. $I$ strip biopsy therapeutically
to Cho 1988;23:373-85.

10 Hamada T, Yoshimine H, Kubota H, et al. Endoscopical resection for early gastric cancer measuring $1 \mathrm{~cm}$ or less in size. Ito Cho 1991;26:255-63.

11 Niwa Y, Nakazawa S, Yoshino J, et al. Quantification of gastric ulcer healing by endoscopic ultrasonography. Gastrointest Endosc 1990;36:116-22. 